neuralgia, and he had known several cases in which the patient had received treatment to the arm itself, whereas the arm was affected only as part of the cerebral syndrome.

In reply to Dr. Hoffman, Dr. Purdon Martin said that the younger the patient the more likely was the lesion, low or high, to be a disc lesion, but in older patients arthritic conditions came much more into the picture. He believed that osteo-arthritis made the disc more brittle and caused greater liability to adhesions.

The President said that in his hospital the experience of disc injuries and their treatment corresponded with that of Dr. Purdon Martin. The orthopaedic department and the neurosurgical department worked closely together and the neuro-surgeons carried out the operations on the discs-on lumbar discs about three or four hundred to three or four (that sort of figure) on cervical discs. He had been impressed by the case of a man who came to the out-patient department with intense pain in both arms, deformity of the neck, and spastic muscles. He was admitted to hospital and the diagnosis of cervical disc lesion, with all the neurological signs, was made. The man could not be made comfortable, and, therefore, under pentothal he had gently stretched the neck and put him in plaster, and within two days he was free from pain. Only that same morning he had seen him walking about in the ward quite without pain, and the neurological signs were quickly receding. A little numbness over the thumbs was all that appeared to be left. Apart from rest in bed, it did appear that plaster was a good thing.
Dr. K. N. LloyD said that, in such cases as Dr. Purdon Martin had described, of osteoarthritis with definite localizing signs, the majority had a narrow disc space in addition to the osteo-arthritis. It was a question which came first. Was it an old disc with secondary osteo-arthritis on the top of it, or was it an osteo-arthritis which had degenerated and had made the disc more liable to rupture? He had the impression that the second of these possibilities was the more likely. It was difficult to find a history of previous trauma and previous brachial neuralgia to account for an early prolapsed disc, and, secondly, most patients had had their symptoms for weeks or months, and often the symptoms came on suddenly. Radiographs showed that the osteo-arthritic changes were too marked to have come in a matter of weeks or months.

Mr. TIPPETT had been impressed in some cases of lesions of a lumbar disc with sciatica by the dramatic relief after simple manipulation. Many cases of brachial neuralgia which might be put down to prolapsed disc lent themselves to ordinary physiotherapy methods.

Dr. L. C. HILl said it was his impression, on seeing some of these cases of neuritis in the arm to which Dr. Fletcher had referred, that those in which the sixth and seventh cervical roots were affected nearly always recovered, either quickly or slowly, whereas those in which the fifth cervical root was affected never, or virtually never, recovered. He wondered whether that was a correct observation, and, if so, whether there was any reason for it.

\title{
ROYAL SOCIETY OF MEDICINE
}

\section{Sections of Medicine and Physical Medicine}

A joint discussion between the sections of Medicine and Physical Medicine of the Royal Society of Medicine, on the aetiology of rheumatism, was held on Jan. 28 in London. This was opened by Dr. W. S. C. Copeman, who reviewed the history and development of the various theories that had been held with regard to aetiology. Dr. Philip Ellman then gave a symposium of the known facts bearing on the causation of rheumatic disease and allied arthropathies, together with photographs and radiographs of cases and some graphs showing the incidence of factors such as age, occupation, worry, shock, poverty, etc., on different rheumatic types. He favoured the unitarian theory of the causation of rheumatism.

Dr. G. D. Kersley followed this summary with a reasoned argument for a sensitization factor as the connecting link between the various syndromes-first 'excluding osteoarthritis as being a disease of joints occasioned by a predisposition to early senility coupled with trauma or repeated microtraumata. The remaining syndromes were all generalized conditions of the mesodermal tissues, and he reviewed the evidence for the hypothesis that they were due to "an altered reaction of the macro-organism to invasion by a foreign protein", and connected all the known aetiological factors either with depression of immune body formation (circulating antibody) or production of allergens. Graphs were shown indicating how the relative proportions of cell-fixed and circulating antibody could account for either the acute or chronic rheumatic states. 